\title{
CORRIGENDUM Tyrosine-612 in PDE5 contributes to higher affinity for vardenafil over sildenafil
}

\author{
R Zoraghi, SH Francis, D Wood, E Bischoff, J Hütter, A Knorr, M Niedbala, I Enyedy, K Pomerantz and \\ JD Corbin
}

International Journal of Impotence Research (2006) 18, 413. doi:10.1038/sj.ijir.3901442

Correction to: International Journal of Impotence Research (2006) 18, 251-257. doi:10.1038/sj.ijir.3901411

The following Acknowledgements section should have been included in this paper:

We especially thank Drs Kenji Omori and Jun Kotera of Tanabe-Seiyaku Pharmaceutical Co. Ltd (Saitama, Japan), for kindly providing human PDE5A1 cDNA. We thank Dr Hengming Ke of the University of North Carolina for reading the manuscript and assisting with interpretation of the results. We also thank Kennard Grimes for his excellent technical assistance. Many reagents were obtained via the Vanderbilt University Diabetes Center core facilities with the aid of Scott Wright, Kris Ellis, and Kennetra Price. DNA sequencing was performed by the Vanderbilt Ingram Cancer Center Sequencing Core facility. This work was supported by Research Grants from NIH DK40299, NIH DK58277, Postdoctoral Fellowship AHA 032525B, and a Grant from Bayer HealthCare AG. 